\title{
Uma desmontagem humanizada através de fotografias em Saúde Coletiva*
}

\author{
Humanized disassembly through photographs within public health \\ Un desmontaje humanizado por medio de fotografías en Salud Colectiva
}

\begin{abstract}
Margem
Margem: contorno externo e imediato de algo. Margear: situar-se em uma relação.

Marginal: sujeito que beira a vida. Marginalista: adepto à criação de anotações em imagens.
\end{abstract}

(Garcia, 2013, p.44)
Kossoy (2007) considera a noção de desmontagem como algo implicado na ideia de decifração. Na busca, através das imagens fotográficas, de suas realidades e seus códigos. Através de uma análise iconográfica e de interpretação iconográfica, detecta seus elementos constitutivos (fotógrafo, assunto, tecnologia) e suas coordenadas de situação (espaço, tempo). Propondo, assim, a reconstituição do processo que originou a representação. Nesse sentido, tratamos de um território-imagem ${ }^{3}$ vivo e em movimento, como se pode ver a seguir.

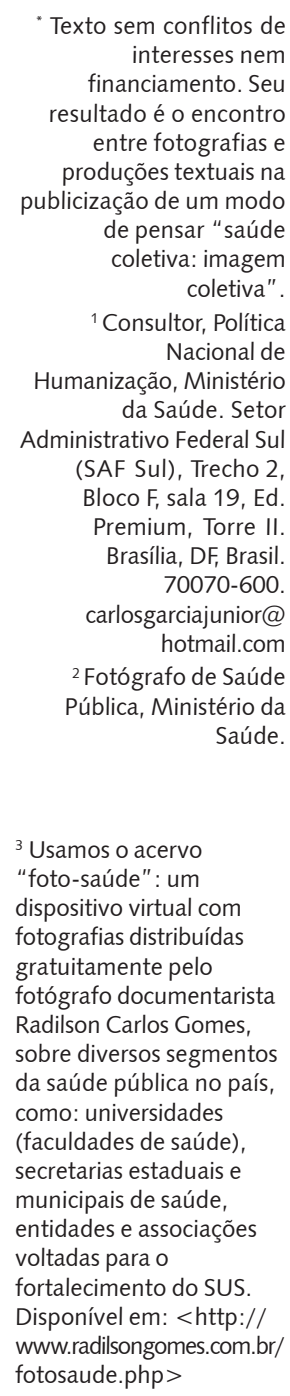
coletiva".

${ }^{1}$ Consultor, Política Nacional de Humanização, Ministério da Saúde. Setor Administrativo Federal Sul

(SAF Sul), Trecho 2

Bloco F, sala 19, Ed.

Bloco F, sala 19, Ed.
Premium, Torre II. Brasília, DF, Brasil. 70070-600. carlosgarciajunior@ hotmail.com ${ }^{2}$ Fotógrafo de Saúde Pública, Ministério da
Saúde.

\footnotetext{
${ }^{3}$ Usamos o acervo

"foto-saúde": um dispositivo virtual com fotografias distribuídas gratuitamente pelo fotógrafo documentarista Radilson Carlos Gomes, sobre diversos segmentos da saúde pública no país, como: universidades (faculdades de saúde), secretarias estaduais e municipais de saúde, entidades e associações voltadas para o

fortalecimento do SUS.

Disponível em: <http:// www.radilsongomes.com.br/ fotosaude.php>
} 
CRIAÇÃO

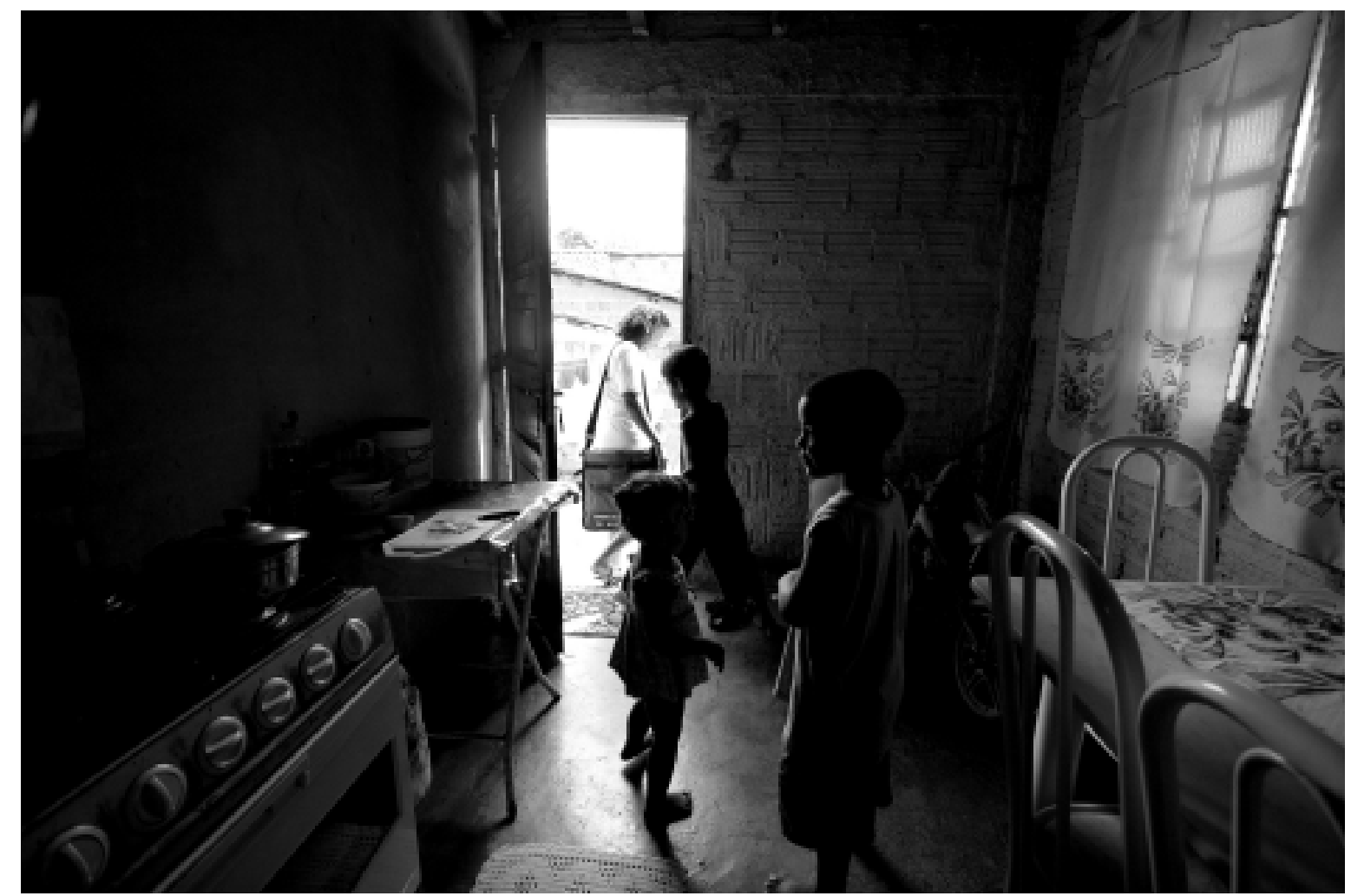

Figura 1. Agente Comunitário da Saúde, Cuiabá

Vida-família. Cozinha, ponta de alimento, porta de entrada. Cozinha-família, entrada da vida. Domicílio, meio de vida, meio da vida. Visita, todos entram. Visita domiciliar, aquela em busca (se ativa). Tempo de conversas, barriga cheia e calor. Tempo de silêncio, panela vazia e desânimo. A imagem além de compor contrastes de luzes e momentos, apresenta uma abertura para enxergarmos a partir de um lugar de "dentro", ao mesmo tempo, um lugar de "fora", e perder-se naquilo que não se vê. Tem-se a proteção de paredes entre a vida pública e a vida privada. A saúde (ora pública) tenta entrar na casa (ora privada) pela porta aberta. Vida e família, bem público-privado, porta de entrada de tudo. 


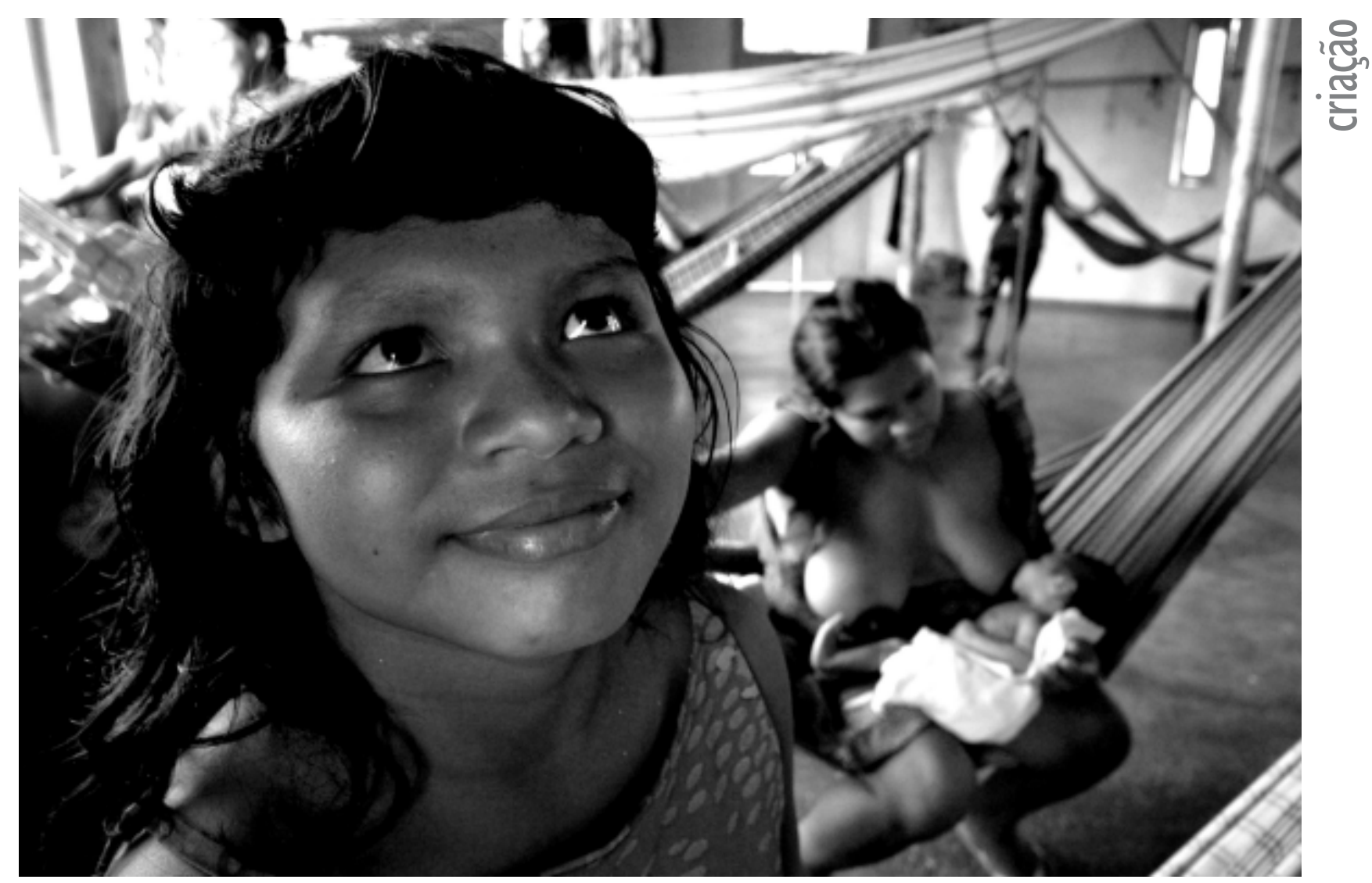

Figura 2. Casa de Saúde Indígena, Itacoatiara, Amazonas

"Dona de divinas tetas, derrama o leite bom na minha cara e o leite mau na cara dos caretas", diria Caetano Veloso na música "Vaca Profana". Leite, alimento sagrado e acalentador. Seios e bustos, imagem divina da vida. Vida fértil, vida pulsante. História revelada na transmissão e na passagem do líquido. Hoje, mãe. Ontem, jovem. Amanhã, senhora. Entre rios, sinuosas margens que revelam a mãe natureza resguardada pela vida ainda humana. Um olhar feminino. Mulheres, mães, meninas e avós de um povo que carrega uma herança. Uma cultura com seus respeitos e seus rituais. Entre redes, entre pontos, entre vidas. A naturalização de vidas em redes. Num primeiro plano: olhos abertos-acima, atentos ao fora. No segundo plano: olhos fechados-abaixo, atentos ao cuidado (dentro). 


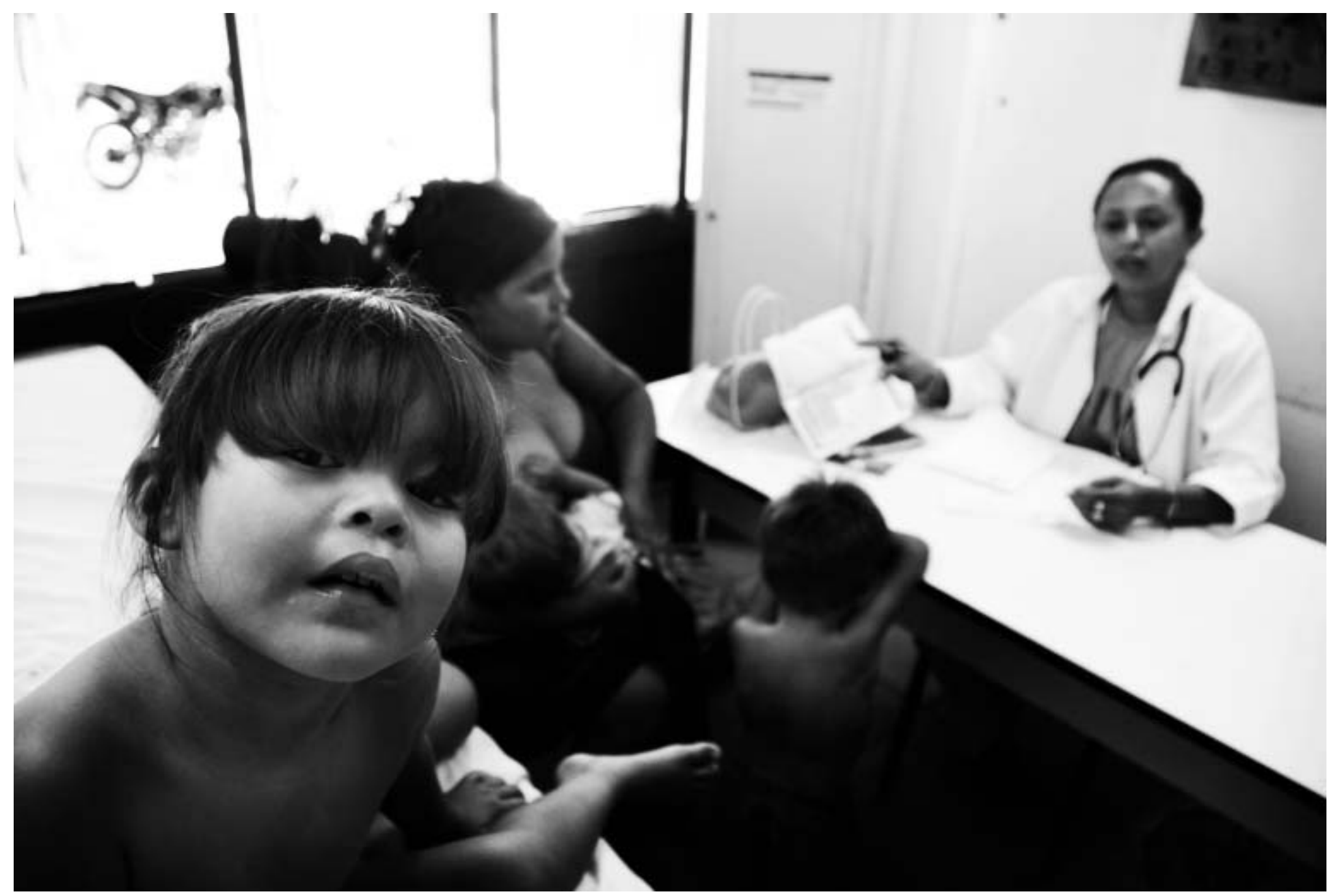

Figura 3. Unidade Básica de Saúde, Parnaíba, Piauí

Uma mesa em distâncias. Entre histórias de distâncias e distâncias de histórias, mulheres e crianças numa ciranda. Uma família viva, uma passagem de tempo, em busca de cuidado. Perguntas: quem quer atenção quer encontrar solução? Quem escuta visa qual saída? Quem olha, diz o quê? Com licença, doutora, entramos aqui para saber o que temos, mas acho que só sabemos o que não temos. 


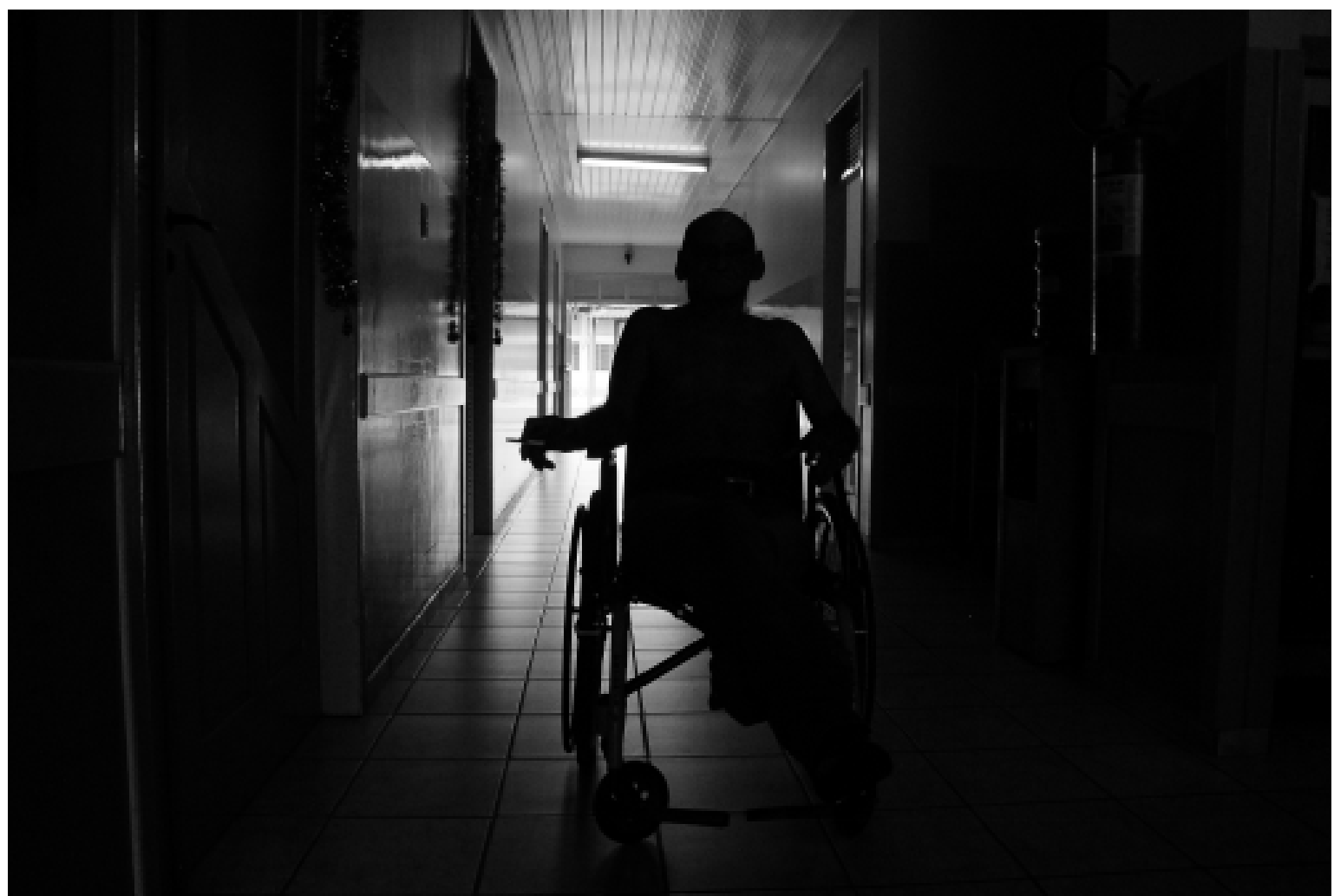

Figura 4. Colônia de hanseníase, Colônia João Paulo II - Marituba, Pará

Tem fogo? Indagaria parado. Como se o caminho já não revelasse nenhuma surpresa. Um caminho que há muito se caminha sabendo para onde se vai. Já foram deixados pelo percurso alguns restos de cinzas. Fogo? Claro! Prazeres e paixões não se esvaem em si mesmas, elas conduzem caminhos, avisam aos menos atentos. Sinais e alertas que advertem, dizem de sua saúde. Caminhar parado e rodar em rodas. No escuro, num corredor solitário, vive restos e fumaças. Se já lhe amputaram as pernas, do que lhe servem, se o corpo segue a andar? 
CRIAÇÃO

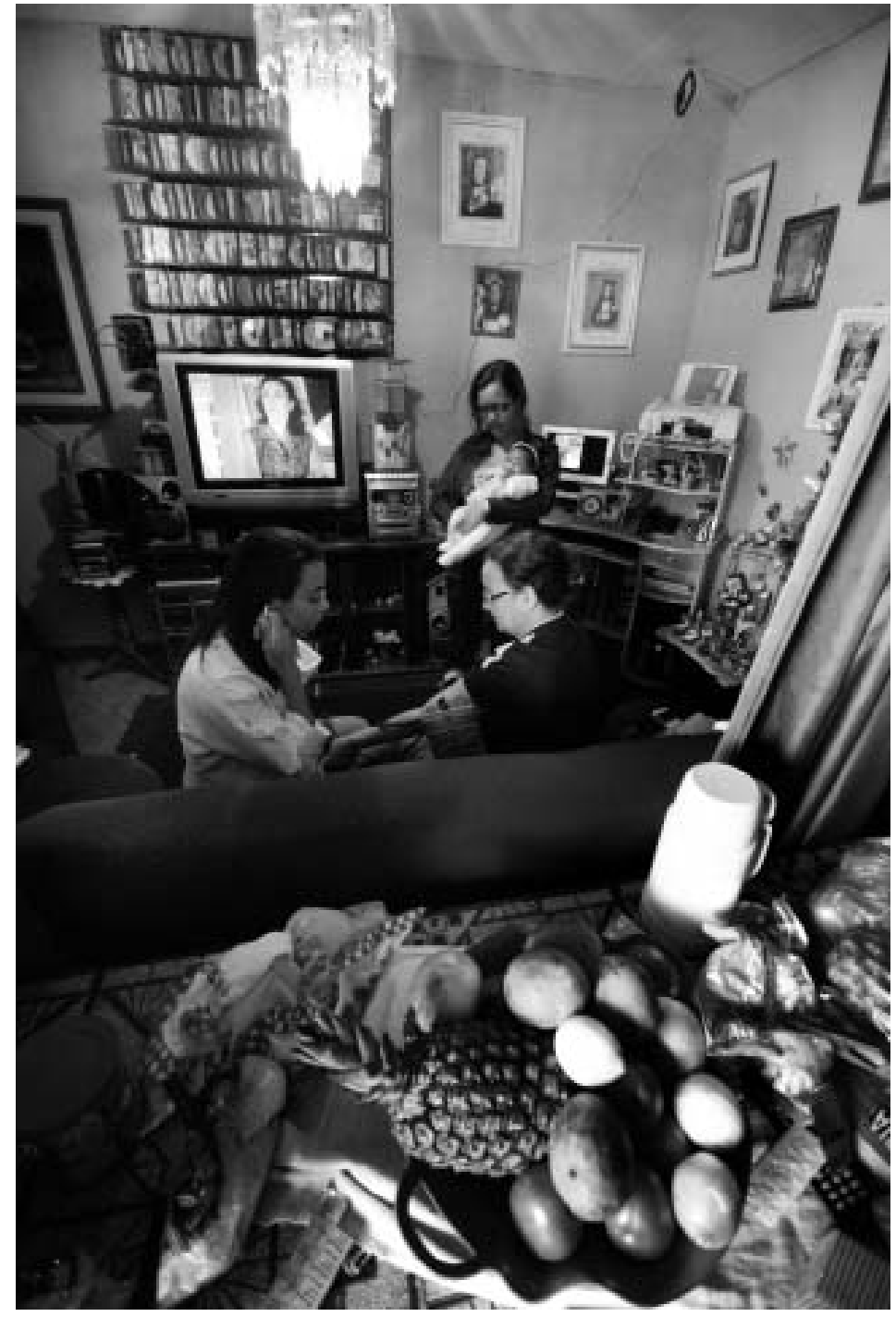

Figura 5. Atendimento domiciliar, periferia de São Paulo, SP

Planos em três porções, divididos entre pequenos objetos humanos. Conversas e condições. Mulheres postas a dialogar sobre a vida, banalidade em forma de uma tela. Um emaranhado de semicoisas entre a vida. Vale a pena ver de novo. Quem não vê perde a chance de chegar, e quem chega é porque quis ver. Uma visita abre o impulso de organizar a casa. O estranho que entra sempre pode estranhar aquela casa. Como se tentássemos mostrar um pouco daquele outro que não somos. Um visitante impõe um reajuste. O relógio, a mobília, a bagunça habitual da vida passa a ser um possível desconforto. 


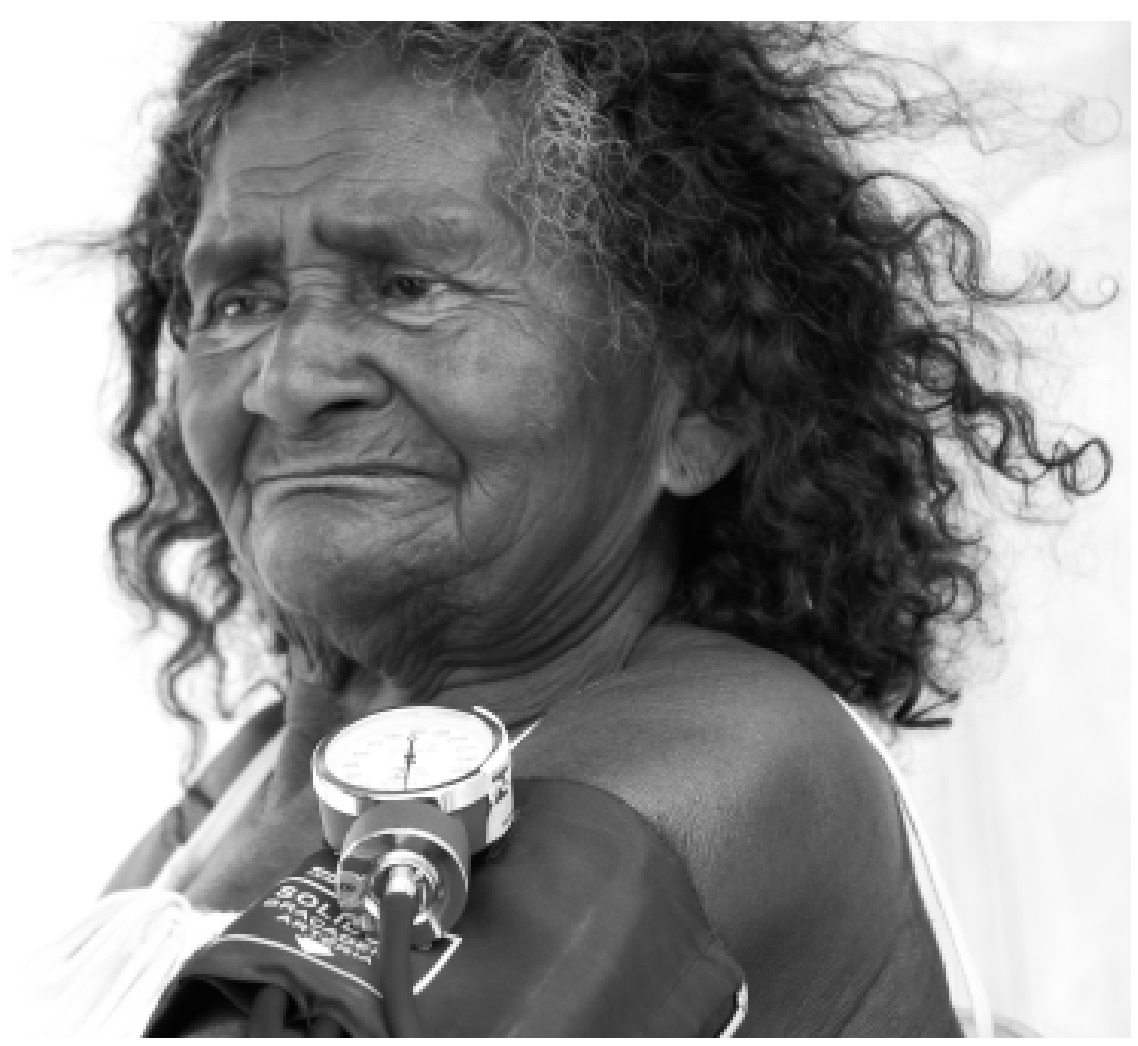

Figura 6. Ananindeua, Pará

Pressões e marcas, impressões de expressões. Pressões e contrastes, menção de tensão. Se o olhar e o vento não conseguem revelar um tempo ou, mesmo, um lugar, ao menos, pode-se ter um instante já-mais (Garcia, 2013) o mesmo. Instante já-mais o mesmo é incapacidade de prender, escolha de extrair o medo e o fim. Entre medidas capazes de relevar a normalidade, temos sujeitos comuns, vida legítima, base sólida de um território. Medidas e médias. Normalização que varre extremos que jamais se tocam. Minha amiga, como vai você? Ainda que não nos conhecemos, mas sei quem é você. Você entrou em minha casa e esqueceu-se de dizer seu nome. Pediu uma xícara de açúcar, um pedaço de pão e nunca mais voltou. Deixou de aparecer. Por favor, apareça minha amiga, e diga quem realmente é você. 
CRIAÇÃO

\section{Colaboradores}

Os autores trabalharam juntos na concepção desta publicação. Carlos Garcia Jr. produziu o texto e Radilson Carlos Gomes fotografou as imagens.

\section{Referências}

GARCIA, S. Marginais. Rio de Janeiro: Multifoco, 2013.

KOSSOY, B. Os tempos da fotografia: o efêmero e o perpétuo. Cotia: Ateliê Editorial, 2007.

Recebido em 14/06/13. Aprovado em 31/10/13

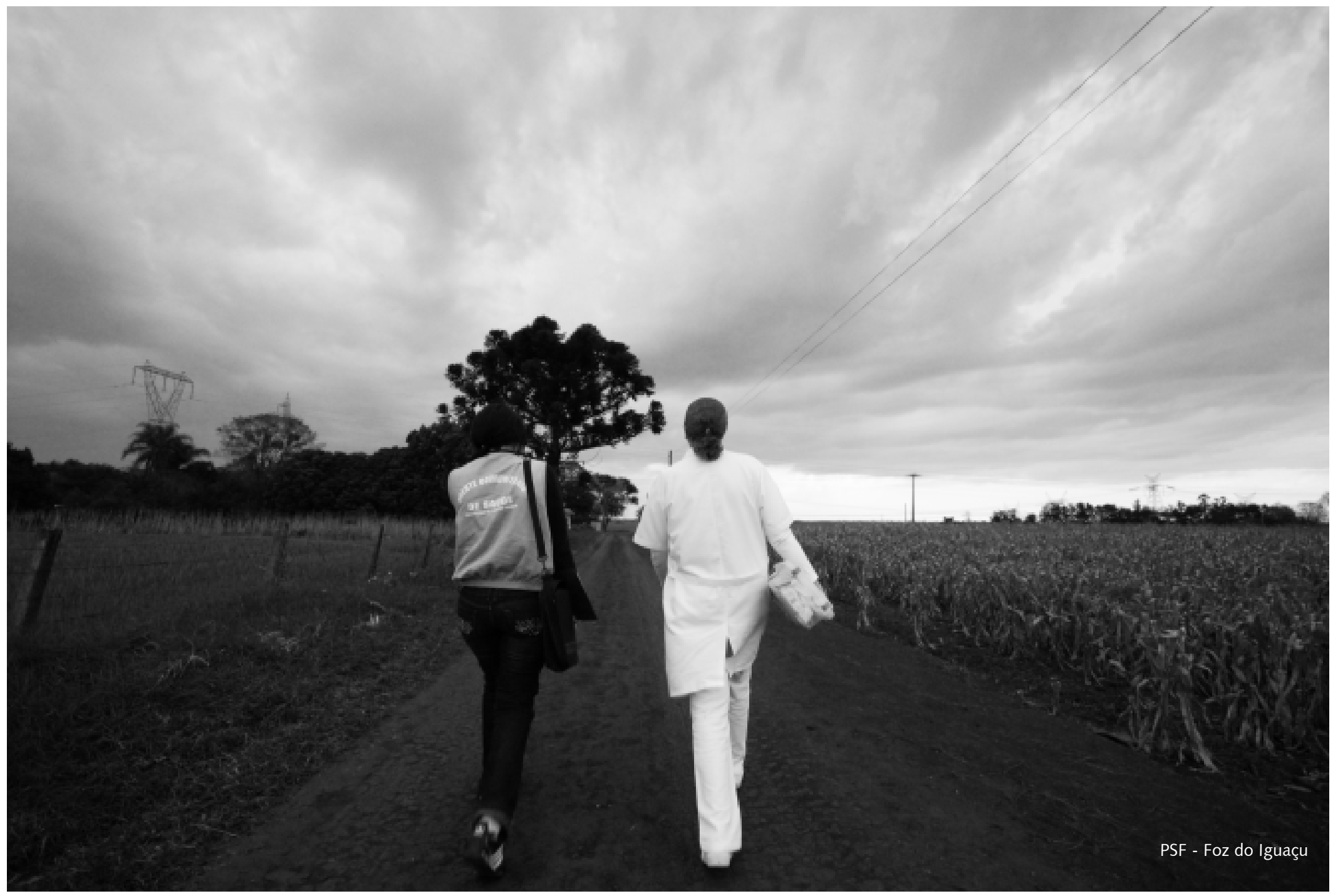

1002 interface comunicação saúde educação v.17, n.47, p.995-1002, out./dez. 2013 